\title{
Preconditioning somatothermal stimulation on Qimen (LR14) reduces hepatic ischemia/reperfusion injury in rats
}

Cheng-Chu Hsieh ${ }^{1,2 \dagger}$, Shu-Chen Hsieh ${ }^{3 \dagger}$, Jen-Hwey Chiu ${ }^{4,5^{*}}$ and Ying-Ling $\mathrm{Wu}^{1^{*}}$

\begin{abstract}
Background: In human beings or animals, ischemia/reperfusion (I/R) injury of the liver may occur in many clinical conditions, such as circulating shock, liver transplantation and surgery and several other pathological conditions. I/R injury has a complex pathophysiology resulting from a number of contributing factors. Therefore, it is difficult to achieve effective treatment or protection by individually targeting the mediators. This study aimed at studying the effects of local somatothermal stimulation preconditioning on the right Qimen (LR14) on hepatic I/R injury in rats.

Methods: Eighteen male Sprague-Dawley rats were randomly divided into three groups. The rats were preconditioned with thermal tolerance study, which included one dose of local somatothermal stimulation (LSTS) on right Qimen (LR14) at an interval of $12 \mathrm{~h}$, followed by hepatic ischemia for $60 \mathrm{~min}$ and then reperfusion for $60 \mathrm{~min}$. Serum aspartate aminotransferase (AST) and alanine aminotransferase (ALT) have been used to assess the liver functions, and liver tissues were taken for the measurements such as malondialdehyde (MDA), glutathione (GSH), catalase (CAT), superoxidase dismutase (SOD), and myeloperoxidase (MPO).
\end{abstract}

Results: The results show that the plasma ALT and AST activities were higher in the I/R group than in the control group. In addition, the plasma ALT and AST activities decreased in the groups that received LSTS. The hepatic SOD levels reduced significantly by I/R injury. Moreover, the hepatic MPO activity significantly increased by I/R injury while it decreased in the groups given LSTS.

Conclusions: Our findings show that LSTS provides a protective effects on the liver from the I/R injury. Therefore, LSTS might offer an easy and inexpensive intervention for patients who have suffered from I/R of the liver especially in the process of hepatotomy and hepatic transplantation.

Keywords: Ischemia-reperfusion, Qimen (LR14), Superoxidase dismutase, Myeloperoxidase

\section{Background}

In human beings or animals, ischemia-reperfusion (I/R) injury of the liver may occur in many clinical conditions, such as circulating shock [1], disseminated intravascular coagulation [2], liver transplantation and surgery [3], cardiac failure and arrest, alcohol toxicity and several other pathological conditions. Different injury mechanisms contribute to the overall pathophysiology of the

\footnotetext{
* Correspondence: chiujh@mailsrv.ym.edu.tw; wuyl@ntu.edu.tw ${ }^{\dagger}$ Equal contributors

${ }^{4}$ Division of General Surgery, Department of Surgery, Veterans General Hospital, Taipei 112, Taiwan

'Department and Institute of Veterinary Medicine, School of Veterinary Medicine, National Taiwan University, Taipei 106, Taiwan

Full list of author information is available at the end of the article
}

hepatic I/R injury. Because the liver is a highly oxygenutilizing organ; therefore, the impairment of blood flow will rapidly cause hepatic hypoxia, which may progress to absolute anoxia especially in the pericentral regions of the liver lobe $[4,5]$. Therefore, it is very important to investigate the proper treatments for the $I / R$ injury of the liver.

Oxygen-derived free radicals play a crucial role in $I / R$ injury in many organs such as the heart and the liver $[6,7]$. Among the systemic consequences of reperfusion, lipid peroxidation is probably the most severe effect caused by free radicals, which results in structural and functional derangement and death of cells eventually $[8,9]$. Several lines of evidences have shown that HSP70 
is a general anti-apoptotic protein, which protects cells from cytotoxicity induced by oxidative stress or chemotherapeutic agents [10].

Among the numerous complementary and alternative medicine therapies, acupuncture and moxibustion are ancient Chinese therapies that are most widely accepted as in the treatment of many diseases. There have been various studies on the mechanisms and efficacy of acupuncture and moxibustion. In addition, many researchers using the protocols of evidence-based medicine have proved that acupuncture is effective in treating chronic low back pain and digestive disorders [11], and also found moxibustion preconditioning protects the ischemic and anoxic brain tissue by increasing the activity of endogenous antioxidase [12]. Moreover, many hypotheses have been proposed to address the physiological mechanisms mediated by the action of acupuncture and moxibustion. In general, a large number of scientific studies have recently established strong evidence on the higher efficacy of acupuncture and moxibustion based on their clinical use over millenniums of years than that of the traditional treatment [13-15].

There are many modalities, including chemical and physical preconditioning, used to protect the organs from I/R injury. Massage, acupressure, chiropractic health care, exercise and hyperthermia et al. have been employed as treatment strategies for neuromuscular disorders or other diseases [16-19]. Recently, preconditioned local somatothermal stimulation (LSTS) has been proved to protect the heart and liver, increaseing the neuromuscular plasticity against I/R injury [20]. Therefore, LSTS is a maneuver similar to local heat therapy or the moxibustion technique in traditional Chinese medicine. Moreover, previous studies have demonstrated that the preconditioned LSTS on the right seventh intercostal nerve territory could increase hepatic HSP70 synthesis and protect the liver from I/R injury in rats [21]. Interestingly, the critical temperature evoking such visceral responses was around $41^{\circ} \mathrm{C}$ to $43^{\circ} \mathrm{C}$, which was similar to those inducing HSP expression in a wide range of studies [21-24]. The induction of HSPs may afford protection from subsequent insults by decreasing leukocyte infiltration of postischemic tissues [25].

In our previous study, there are two possibilities to explain a somatovisceral reflex, namely, meridian theory and neuro-reflex theory. In meridian theory, Qimen (LR14) is an acupoint in the liver meridian. Accumulating evidence has demonstrated that there are convergent connections between somatic- and visceral neurons of the same or similar nerve territory during embryonic development. Besides, there is evidence that stimulation on an acupoint would regulate the corresponding organs through a complete loop of somatovisceral reflex, including receptors, afferent limbs, central system, efferent limbs and the target organ. Our previous work has demonstrated that the visceral response inhibited by blocking the afferent limb was blocked by local anesthesia [23]. Nonetheless, the possibility of the involvement of meridian theory can not be completely ruled out. In this study, we proved that the application of LSTS to the right Qimen (LR14) could induce the hepatic gene expression of HSP70, and this paper mainly focuses on whether LSTS passes through different pathway to protect the liver against subsequent I/R injury?

\section{Methods \\ Animals}

Eighteen male Sprague-Dawley rats each weighing 250-300 g, had been obtained from the animal center of the National Science Council, Taiwan, Republic of China. They were fed with standard diets and water ad libitum and treated under the regulations of the "Guide for the Care and Use of Laboratory Animals" (National Academy Press; 2011). The studies of these rats were approved by the ethics committee for animal study of National Yang-Ming University, Taipei, Taiwan, Republic of China.

\section{Local heat stress by local somatothermal stimulation}

Application of local heat stress instead of using wholebody hyperthermia had been achieved by means of LSTS on skin areas with no direct contact with the skin surface. Conventional application of local heat therapy is supposed to evoke multiple sensory stimulation such as temperature, pressure, pain, and touch. In order to avoid causing any interference with the data interpretation by such multisensory stimulation, temperature was used as the sole stimulator in this study. The effect of LSTS done by using a heat generator (120 Watt. electric heating rod, Jise Co.) had been reported in our previous study regarding its relaxation effects on the sphincters of Oddi in cats, rabbits and the internal sphincters in rabbits $[22,24]$. In brief, LSTS had been achieved by the application of a heat generator supplying a single heat source on and above the skin areas when the skin temperature fluctuated above and below the critical point of $41^{\circ} \mathrm{C}$. This was done by intermittently turning the switch of the heat generator on and off, namely, $4 \mathrm{~min}$ on and $5 \mathrm{~min}$ off for three courses [23]. In total, one dose of LSTS was completed in $27 \mathrm{~min}$. A tinfoil paper with holes of $0.5 \mathrm{~cm}$ in diameter had also been used so that the heat generator could just focus on one point above the skin surface without insulation. Finally, we used a digital displayed thermometer to confirm that the critical heat point $\left(41^{\circ} \mathrm{C}\right)$ was reached. 


\section{Preconditioning by LSTS}

To study the modulatory effect of preconditioned LSTS on the livers of I/R injury, the heat generator was applied to $0.5 \mathrm{~cm}$ above the right Qimen (LR14), which was just at the junction of the right mid-clavicular line and the sixth intercostal space (Figure 1). The rats were anesthetized with Ketamine $(50 \mathrm{mg} / \mathrm{kg}$, intraperitoneal injection (IP)), and the skin was shaved at the stimulus application point. The preconditioning LSTS was applied $12 \mathrm{~h}$ prior to the I/R liver injury.

\section{Animal model and parameters for the I/R injury of the liver}

The model of rats with $I / R$ injury was created as previously described [26,27]. In brief, male Sprague-Dawley rats were anesthetized with urethrane $(1.25 \mathrm{~g} / \mathrm{kg}$, IP), and the trachea was cannulated for artificial respiration with a ventilator. Polyethylene (PE-50) catheters were cannulated into the femoral artery to monitor the blood pressure with a polygraph (Gould, RS 2400). The liver was exposed through an upper midline incision, and two pieces of fine silk were looped along the right and left branches of the portal vein, hepatic artery, and bile duct. The procedure whereby the silk was inserted into a snare with a piece of polyethylene (PE-90) which allowed the occlusion of the blood supply to either the median and left lobes (left branch). For the I/R injury study, ischemia of the median/left lobes were maintained for $60 \mathrm{~min}$ followed by reperfusion of the median/left lobes with immediate occlusion of the right lobe vasculature for another $60 \mathrm{~min}$. One hour after the completion of the reperfusion procedure, the initial ischemicreperfused median/left lobes were resected and tested for myeloperoxidase (MPO), malondialdehyde (MDA), glutathione $(\mathrm{GSH})$, catalase (CAT), superoxidase dismutase (SOD) measurement. Blood samples for ALT/ AST measurement were collected immediately after the femoral catheterization and the completion of the reperfusion procedure.

\section{Experimental groups}

Eighteen male Sprague-Dawley rats were randomly divided into three groups, which were the: control, I/R and $I / R+$ LSTS groups, where each group had six rats $(n=6)$. In the control group, none of the rats were treated with LSTS, nor subjected to the I/R liver injury. In the $I / R$ group, the rats were subjected to $60 \mathrm{~min}$ of hepatic ischemia followed by $60 \mathrm{~min}$ of reperfusion period. In the I/R + LSTS group, the rats were preconditioned for thermal tolerance study, which included one dose of LSTS on the right Qimen (LR14) at an interval of $12 \mathrm{~h}$ then hepatic ischemia for $60 \mathrm{~min}$ followed by reperfusion for $60 \mathrm{~min}$.

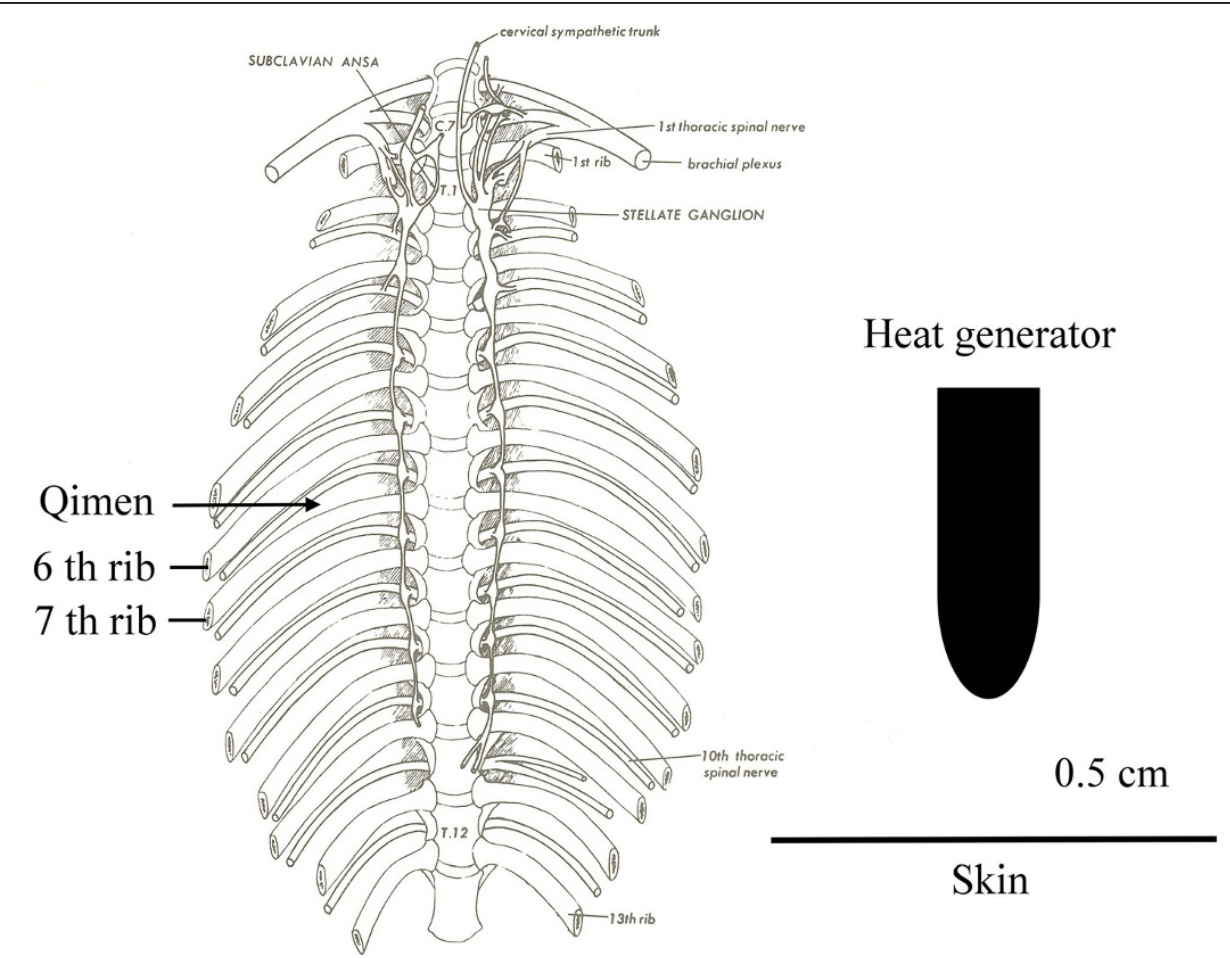

Figure 1 Anatomical and acupoint position. The heat generator was applied to $0.5 \mathrm{~cm}$ above the right Qimen (LR14), just at the junction of right midclavicular line and the sixth intercostal space. 


\section{Biochemical analysis Hepatic SOD assay}

The hepatic SOD activity was determined by using a commercialized chemical SOD assay kit (Cayman Chemical Co.). The kit utilizes a tetrazolium salt for the detection of superoxide radicals generated by xanthine oxidase and hypoxanthine. The collected $1 \mathrm{gm}$ of liver tissues were homogenized in $5 \mathrm{ml}$ of cold buffer $(20 \mathrm{mM}$ HEPES buffer, $\mathrm{pH}$ 7.2, containing $1 \mathrm{mM}$ EDTA, $210 \mathrm{mM}$ mannitol, and $70 \mathrm{mM}$ sucrose) and centrifuged at $1,500 \times g$ for $5 \mathrm{~min}$ at $4^{\circ} \mathrm{C}$. The reaction was initiated by adding xanthine oxidase and incubating at room temperature for $20 \mathrm{~min}$, and then, the absorbance of each sample was read at $450 \mathrm{~nm}$.

\section{Hepatic CAT assay}

The CAT activity was determined by using a commercialized chemical CAT assay kit (Cayman Chemical Co.). The kit utilizes the peroxidatic function of CAT for the measurement of enzyme activity. The collected $1 \mathrm{gm}$ of liver tissues were homogenized in $5 \mathrm{ml}$ of cold buffer (50 mM potassium phosphate, $\mathrm{pH} 7.0$, containing $1 \mathrm{mM}$ EDTA) and centrifuged at $10,000 \times g$ for $15 \mathrm{~min}$ at $4^{\circ} \mathrm{C}$. The samples were then mixed sequentially with hydrogen peroxide; potassium hydroxide, Purpald $^{\circ}$, and potassium periodate and were read at $540 \mathrm{~nm}$.

\section{Hepatic GSH assay}

The hepatic levels of GSH were determined by using a commercialized GSH assay kit (Cayman Chemical Co., Ann Arbor, MI, USA). Cayman's GSH assay kit utilizes a carefully optimized enzymatic recycling method which uses glutathione reductase for the quantification of GSH. The collected $1 \mathrm{~g}$ of liver tissues were first homogenized in $5 \mathrm{ml}$ of cold buffer (i.e., $50 \mathrm{mM}$ MES or phosphate, $\mathrm{pH} 6-7$, containing $1 \mathrm{mM}$ EDTA) and centrifuged at $10,000 \times g$ for $15 \mathrm{~min}$ at $4^{\circ} \mathrm{C}$ followed by metaphosphoric acid deproteinization. After adding triethanolamine solution and Assay Cocktail [a mixture of MES buffer $(11.25 \mathrm{ml})$, reconstituted cofactor mixture $(0.45 \mathrm{ml})$, reconstituted enzyme mixture $(2.1 \mathrm{ml})$, water $(2.3 \mathrm{ml})$, and reconstituted DTNB $(0.45 \mathrm{ml})]$, total GSH in each of the deproteinated samples was measured at $405 \mathrm{~nm}$.

\section{Hepatic MPO assay}

MPO activity was measured from liver tissues using a procedure similar to that documented by Hillegas et al. [28]. The collected $1 \mathrm{~g}$ of liver tissue samples were homogenized in $15 \mathrm{ml}$ of potassium phosphate buffer (PB, $50 \mathrm{mM}, \mathrm{pH}$ 6.0) and centrifuged at $41,400 \times \mathrm{g}$ for $10 \mathrm{~min}$. The pellets were then suspended in $50 \mathrm{mM} \mathrm{PB}$ containing $0.5 \%$ hexadecyl trimethyl ammonium bromide (HETAB). After three freezing and thawing cycles with sonication between cycles, the samples were next centrifuged at $41.400 \times g$ for $10 \mathrm{~min}$. Each aliquot $(0.3 \mathrm{ml})$ was then added to $2.3 \mathrm{ml}$ of a reaction mixture containing $50 \mathrm{mM} \mathrm{PB}, 0.19 \mathrm{mg} / \mathrm{ml}$ o-dianisidine, and $20 \mathrm{mM} \mathrm{H}_{2} \mathrm{O}_{2}$ solution. One unit of enzyme activity had been defined as the amount of the MPO that caused a change in the absorbance measured at $460 \mathrm{~nm}$ for 2 min. MPO activity had been expressed as U/g tissue.

\section{Hepatic lipid peroxidation assay}

The collected $0.5 \mathrm{~g}$ of liver tissue samples were homogenized with $0.01 \mathrm{M}$ sodium phosphate buffer ( $\mathrm{pH} 7.0$ ) $4.5 \mathrm{ml}$. After the addition of $1 \%$ phosphoric acid $1.5 \mathrm{ml}$ and $0.6 \%$ TBA solution $0.5 \mathrm{ml}$, the solution were mixed evenly, and then heated at $95^{\circ} \mathrm{C}$ for $1 \mathrm{~h}$. Phosphorylation of lipid peroxides to be hydrolyzed by boiling, and hydrolysis products of the MDA with TBA (2-Thiobarbituric acid) to produce MDA (TBA) $)_{2}$. Then cool to room temperature, add $2 \mathrm{ml}$ of butanol $\left(\mathrm{C}_{4} \mathrm{H}_{10} \mathrm{O}\right)$, and centrifuged at 2,000 $\times \mathrm{g}$ for $15 \mathrm{~min}$, take butanol layer for ELISA reader at $532 \mathrm{~nm}$ absorbance was measured, and TEP (1,1,3,3-tetraethoxypropane) as the standard value.

\section{Histological analysis}

The rats were sacrificed by decapitation, and small pieces of liver tissues were placed in $10 \%$ ( $\mathrm{vol} / \mathrm{vol}$ ) formaline solution and processed routinely by embedding in paraffin. Tissue sections $(4-5 \mu \mathrm{m})$ were stained with Hematoxylin \& Eosin $(\mathrm{H} \& \mathrm{E})$ and examined under a light microscope.

\section{Data analysis}

The data in each experimental group were analyzed and expressed as means \pm standard error of the mean (SEM). Concentrations of MPO, MDA, GSH, CAT, SOD, ALT, and AST in different groups were determined by using the Wilcoxon rank-sum test to compare the differences between two experimental groups. A $P$ value less than 0.05 indicates statistical significance. Error bars indicates \pm SEM in the figure.

\section{Results}

Hepatic I/R induction and effects of LSTS on Qimen (LR14) During the experimental procedure, blood pressure was continuously monitored using a polygraph. The blood pressure of all experimental rats remained stable, and none of them died during I/R induction. To evaluate the level of liver damage after the reperfusion procedure, blood samples from different groups were collected immediately via the femoral catheters after completing the reperfusion procedure. As shown in Table 1, the ALT and AST levels increased significantly in the I/R group as compared with the control group, while treatment with LSTS ameliorated the increases in ALT and AST. 
Table 1 Plasma ALT and AST activities

\begin{tabular}{lll}
\hline Experimental groups & ALT (U/L) & AST (U/L) \\
\hline Control & $74 \pm 11.2$ & $109 \pm 7.2$ \\
I/R & $843 \pm 131^{*}$ & $1457 \pm 263^{*}$ \\
I/R + LSTS & $505 \pm 75^{*,+}$ & $549 \pm 137^{*},+$ \\
\hline
\end{tabular}

${ }^{*} P<0.05$ : Compared with the control group.

${ }^{+} P<0.05$ : Compared with the I/R group.

The results showed that the plasma ALT and AST activities were higher in the I/R group than in the control group.

These results indicated that the liver damage had been attenuated.

\section{The antioxidant activity of LSTS on Qimen (LR14) in the liver}

Because antioxidant enzymes are important for maintaining an optimal chemical reducing environment to prevent liver from reactive oxygen species (ROS) damage; thus, we analyzed the activities of several hepatic enzymes. As shown in Figure 2, SOD levels were significantly decreased after $I / R$ injury when compared with the control group. Compared with the I/R group, LSTS treatments increased the SOD levels $(P<0.05)$. The level of hepatic CAT in the liver tissue also decreased after $\mathrm{I} / \mathrm{R}$ induction in comparison with control group. Compared with $\mathrm{I} / \mathrm{R}$ group, LSTS treatments revealed comparable amount of CAT (Figure 3). We also measured the level of GSH, which participates in many metabolic processes that protect cells against the actions of free radicals. As shown in Figure 4, the hepatic GSH levels was significantly lower in $I / R$ group than in the control group, whereas the intervention of LSTS in I/R treated mice showed no effects on the level of GSH when compared with $I / R$ group. The mean liver MDA level, an indicator of lipid peroxidation, was also estimated. The MDA value was significantly higher in the I/R group than in the control group. Compared with the $I / R$ group, the mean MDA level was no significant difference in the LSTS group (Figure 5).

\section{The anti-inflammatory effect of LSTS on Qimen (LR14) in the liver}

Because the inflammatory response after I/R plays a critical role in cell damage, we examined the hepatic MPO levels. This enzyme is reflective of tissue infiltration with neutrophils. As shown in Figure 6, the mean hepatic MPO level in the I/R group was significantly increased in comparison to the control group. The MPO level in the I/R group that received LSTS treatment was lower compared with the I/R group $(P<0.05)$.

\section{Histological results}

In the control group, the normal liver parenchyma showed regular morphology of both hepatocytes and

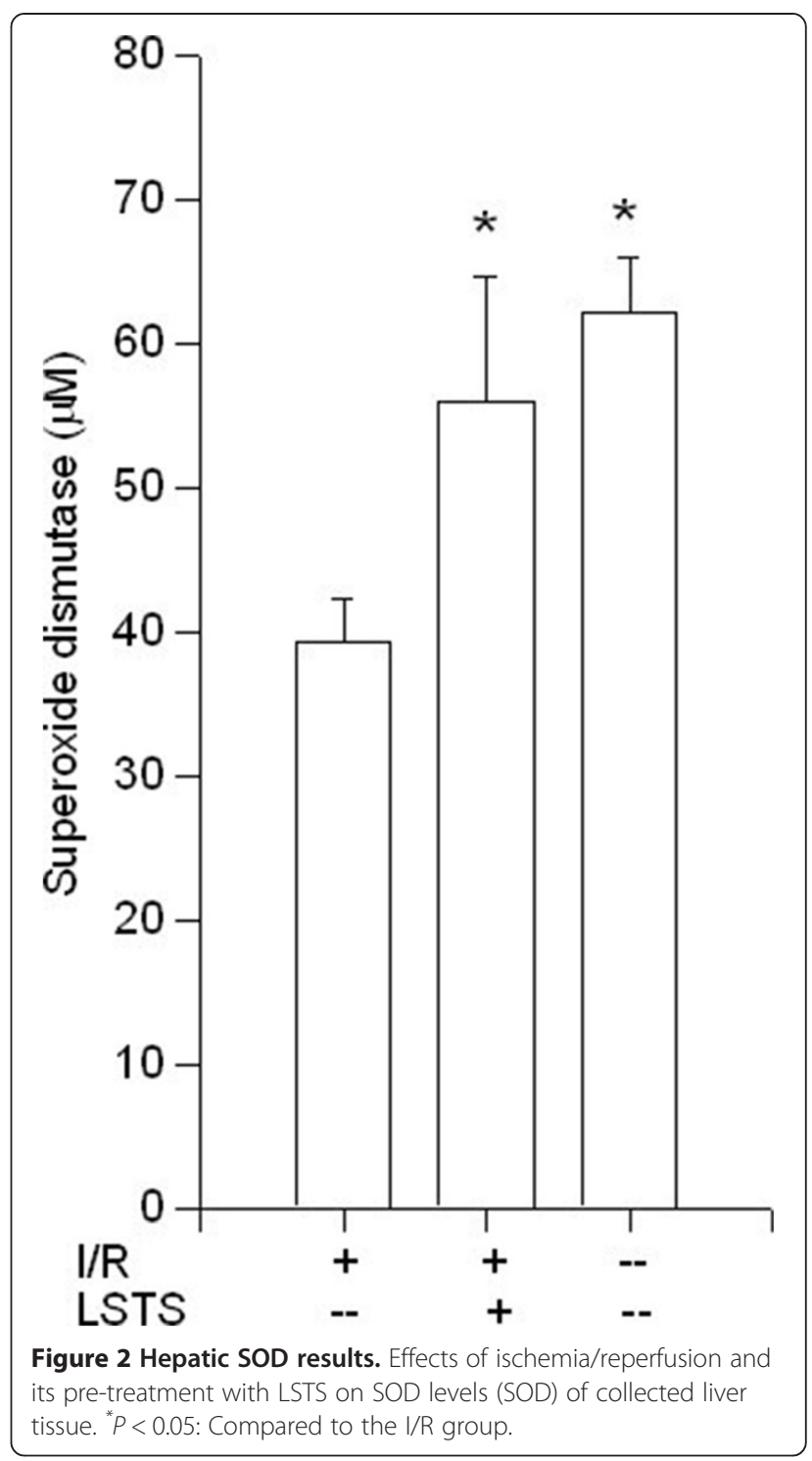

sinusoids around the central vein. In the I/R group, the hepatocytes were prominently swollen with marked vacuolization. Congestions were noticed in enlarged sinusoids. The liver parenchyma were accompanied with irregular morphology of both hepatocytes and sinusoids around the central vein. In the I/R + LSTS group, the hepatocytes and sinusoids displayed normal morphology reflecting well preserved liver parenchyma (Figure 7).

\section{Discussion}

LSTS has been reported to up-regulate the gene expression of HSP70 in livers and preconditioning with LSTS on the right seventh intercostal nerve territory can protect rat livers from $I / R$ injury. In addition, hepatic HSP70 gene expression has been demonstrated to be 


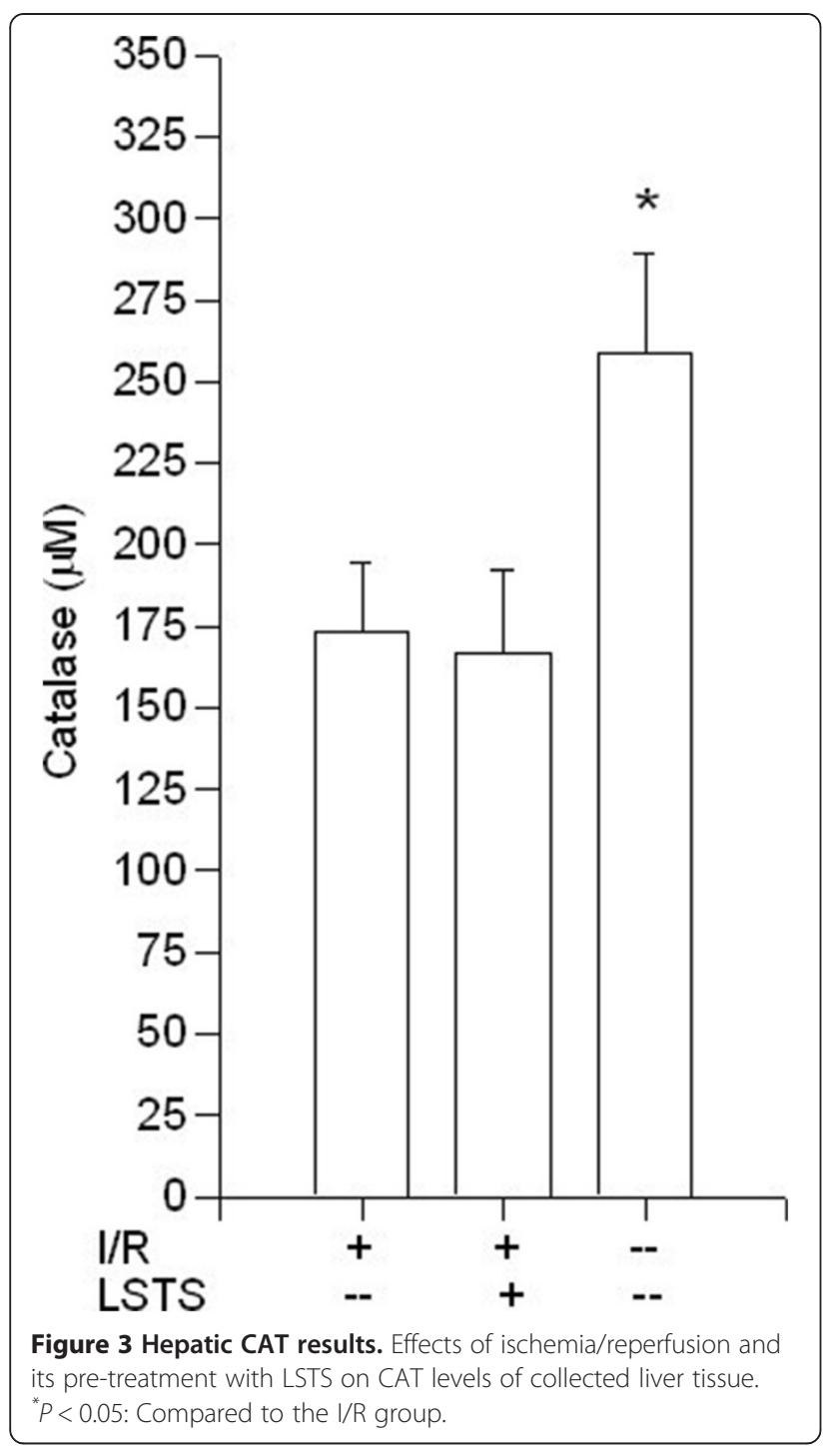

regulated by local heat stress over a designated skin area through a somatovisceral reflex and not by whole-body hyperthermia [21,23].

With regard to the animal model used in this study, it is well-known that the right lobe vasculature occluded with the reperfusion of median/left lobes has been suggested to be a good model for studies on hepatic I/R injury $[21,26,27]$. In the studies on hepatic $I / R$ injury, determinating the time for each $\mathrm{I} / \mathrm{R}$ period is important. Ischemia for too-short $(20 \mathrm{~min})$ or too-long (90 $\mathrm{min})$ time might result in little or irreversible structural and functional changes, respectively. Sinusoidal perfusion failure was found to be aggravated when the ischemic time period was prolonged to $60 \mathrm{~min}$ [29]. Using $60 \mathrm{~min}$ of median/left lobar ischemia followed by $60 \mathrm{~min}$ of reperfusion as a model, our results showed distinct

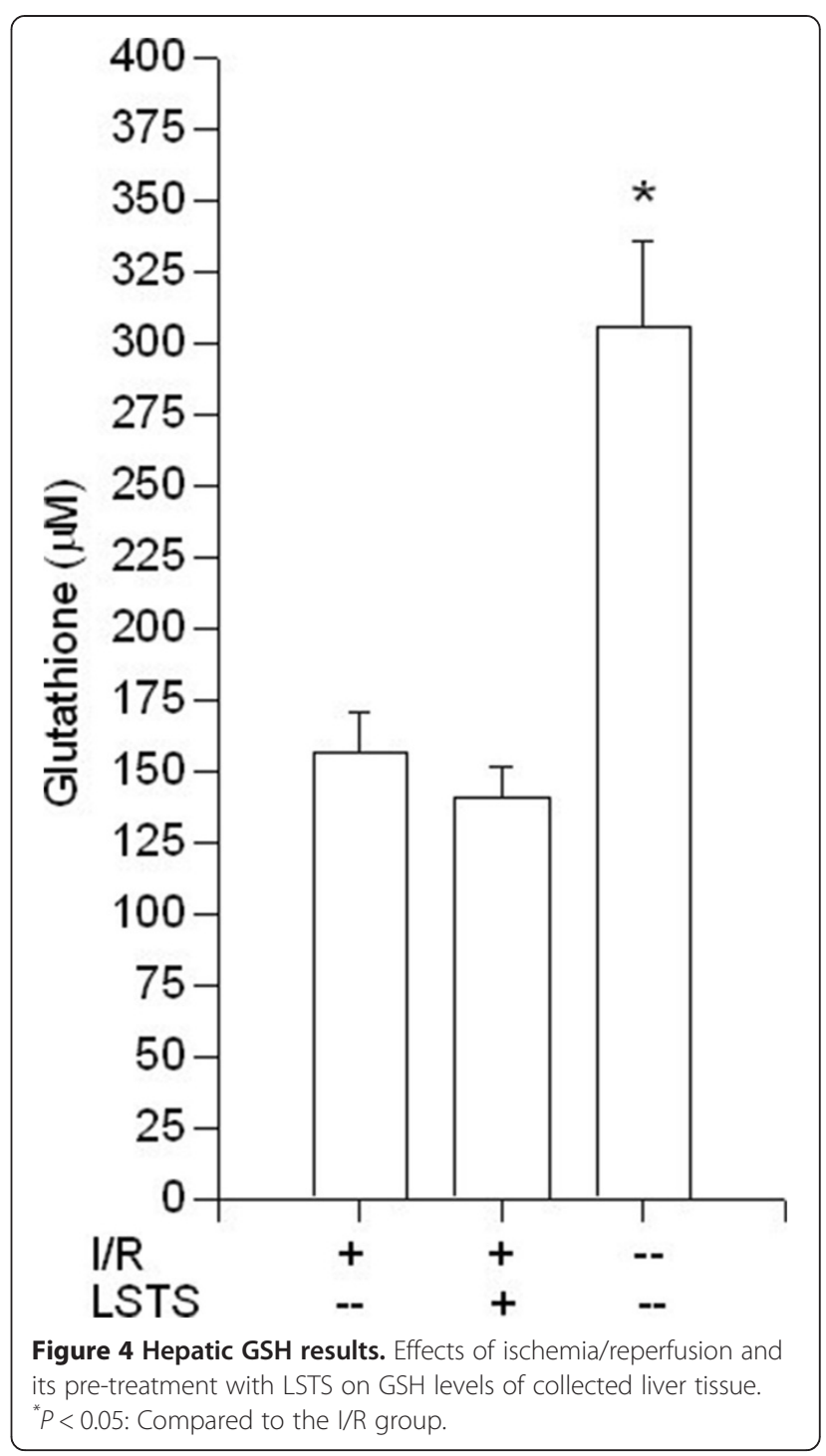

functional alterations (Table 1) and this provided a reproducible system for studying the protective effect of LSTS on hepatocytes from I/R injury.

The I/R injury of livers can occurred in many clinical scenarios including transplantation, trauma and hepatectomy. The main pathophysiological events during this injury comprise depletion of ATP, Kupffer cell activation with subsequent formation of ROS, formation of proinflammatory mediators, and recruitment and activation of macrophages, neutrophils, and lymphocytes. Depending on the severity of the $I / R$ injury, the cell damage can lead to necrotic or apoptotic liver cell death, which can subsequently result in organ dysfunction [30-32]. Oxygen-derived free radicals play an important role in $\mathrm{I} / \mathrm{R}$ injury in many organs like the heart and liver. The aim of these treatments is to restore the blood supply 


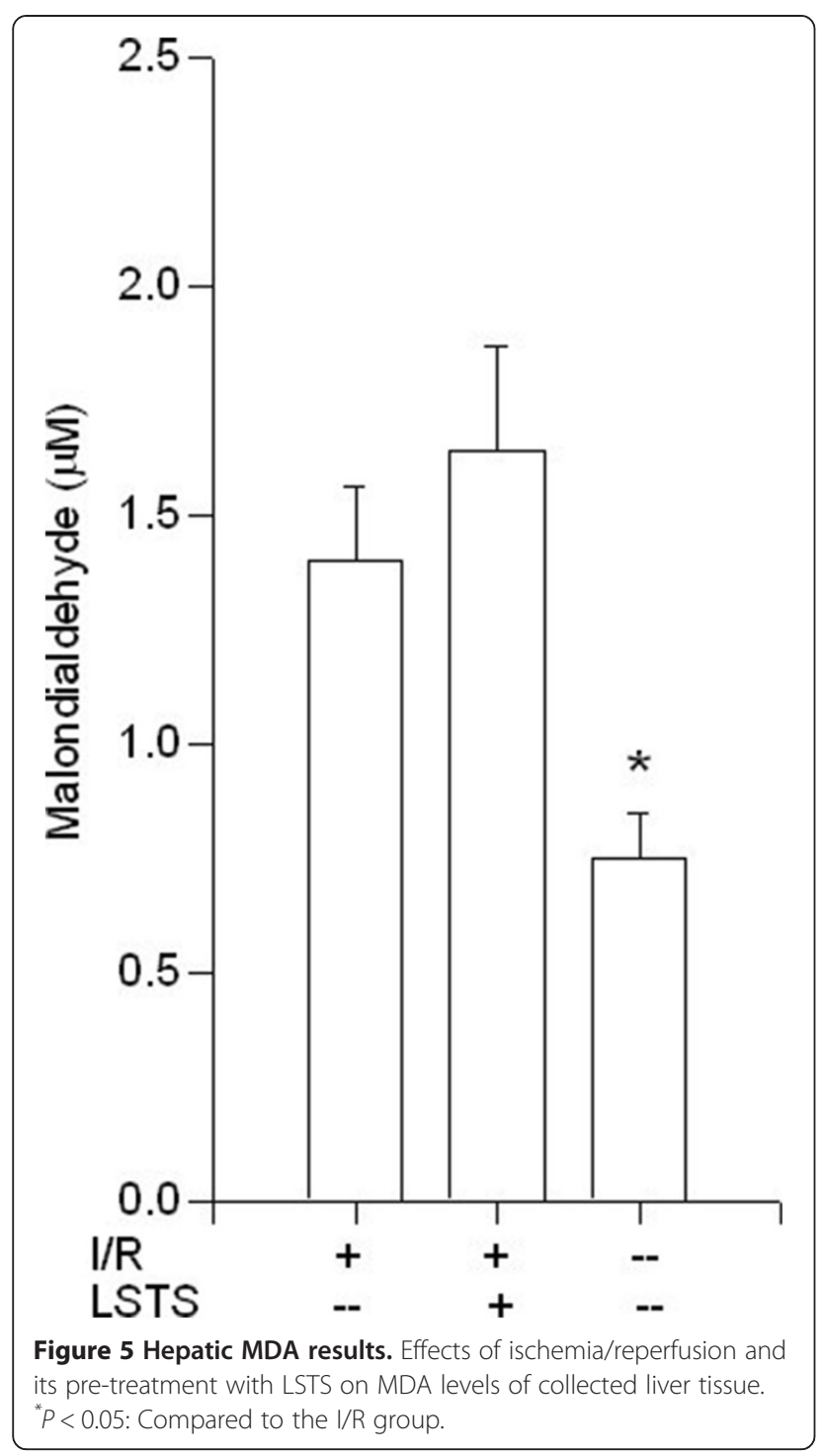

to the ischemic liver. Unfortunately, restoration of the blood flow to ischemic tissues can lead to further damages. This paradox leads to uncertain effectiveness of these strategies. The $\mathrm{I} / \mathrm{R}$ injury is a complex pathophysiology with a number of contributing factors; therefore, it is difficult to obtain effective treatments or protections by targeting individual mediators or mechanisms alone. Preconditioned fasting, ischemia, pharmaceutical molecules, hyperosmolar solutions, and LSTS [23,33-36] have been studied and appear to have the ability to increase the resistance of cells to ischemia and reperfusion events.

In this study, we clearly demonstrated that LSTS on the right Qimen (LR14) up-regulated the levels of SOD and down-regulated the level of MPO in the liver. SOD catalyses the dismutation of the superoxide anion $\left(\mathrm{O}_{2}{ }^{*}\right)$ into $\mathrm{H}_{2} \mathrm{O}_{2}$, which could be transformed into $\mathrm{H}_{2} \mathrm{O}$ and $\mathrm{O}_{2}$ by CAT. In this study, we found that $I / R$ impaired

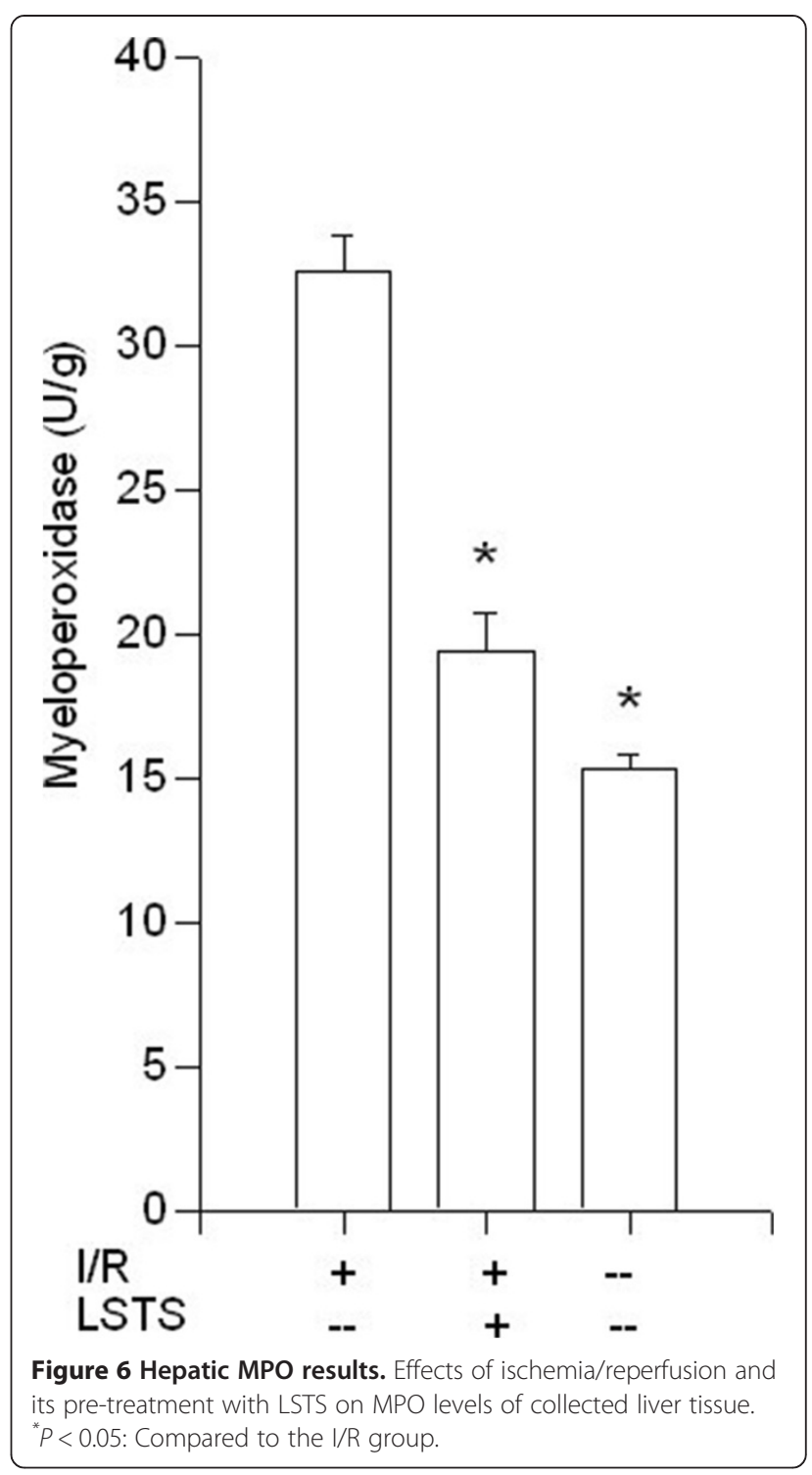

SOD activity as indicated by the markedly lowered activity when compared with the control group. But in the LSTS pretreated group, the decrease of SOD activity was significantly counteracted. HSP70 acts as a molecular chaperone, playing an essential role in mediating protein folding, assembly, transport, and degradation, helping to prevent protein denaturation and aggregation, and assisting in the refolding or removal of damaged proteins $[37,38]$. It has been shown that the SOD activity and its content decrease after the I/ $R$ injury presumably via inactivation of mature and active SOD within mitochondria [39]. It is, however, unlikely that HSP70 could prevent I/R injury induced denaturation or inactivation of mature SOD within mitochondria, because HSP70 localize in different compartments from mature and active SOD. Specifically, HSP70 distributes in cytoplasm and nucleus in both normal and stressed conditions 



Figure 7 Histological results. A. In the control group, the normal liver parenchyme occurred showed regular morphology of both hepatocytes and sinusoids around the central vein (CV). B. In the I/R group, hepatocytes $\left(^{*}\right)$ were prominently swollen with marked vacuolization. Congestion was noticed in enlarged sinusoids. The liver parenchyme took place displayed irregular morphology of both hepatocytes and sinusoids around the central vein. $\mathbf{C}$. In the I/R + LSTS group, hepatocytes and sinusoids represented normal morphology reflecting a well preserved liver parenchyma (400X).

[38,40], while the mature and active SOD exists and acts in mitochondria [41]. It has been clarified that HSP70 plays an essential role in keeping newly synthesized mitochondrial proteins (precursor proteins) in their correct unfolding conformation within the cytoplasm and transporting them into mitochondria [30,31]. Therefore, one should speculate that cytoplasmic HSP70 overexpression could enhance translocation of precursor SOD into mitochondria, which then results in supplementing the pool of mature SOD within these organelles. We have demonstrated that the liver HSP70 overexpression results in improved liver tolerance to I/R injury and is associated with enhanced preservation of the SOD activity.

MPO is an enzyme stored in azurophilic granules of polymorphonuclear neutrophils and macrophages, and released into extracellular fluid in the setting of inflammatory process. MPO is involved in acute and chronic inflammatory diseases. The significant increase in the MPO activity in the liver tissue after hepatic $I / R$ in the present study is consistent with another study [42]. The induction of HSPs may afford protection from subsequent insults by decreasing leukocyte infiltration of post-ischemic tissues [25]. Javadpour et al. found fewer pulmonary neutrophils and less MPO activity after aortic occlusion in rats with prior induction of HSPs via hyperthermia [42] or pharmacologic means [43]. They also showed that hyperthermia prevented decrease in leukocyte rolling velocity induced by mesenteric $I / R$ [44]. Prior hyperthermia also decreases intestinal neutrophil infiltration and mucosal injury after intestinal ischemia [45]. HSP70 may regulate MPO activates to mitigate the $I / R$ injury. In additional, MPO can also serve as an indicator of inflammation and the generation of ROS, because an increase in MPO activity reflects tissue neutrophil infiltration. Neutrophils are a potential source of oxygen free radicals [46] and are considered to be the major effector cells involved in tissue damage that occurs in several inflammatory diseases $[47,48]$. Our results show that LSTS on Qimen (LR14) may decrease MPO activates to reduce hepatic I/R injury.

\section{Conclusions}

Preconditioned LSTS on the right Qimen (LR14) have a beneficial effect on protecting the rat liver against $I / R$ injury. This pre-treatment is more advantageous when compared with the pretreatment by means of whole-body hyperthermia. LSTS is an easily applicable alternative and will bring new perspectives to the clinical prevention of ischemic liver disease or liver transplantation.

\section{Abbreviations}

I/R: Ischemia/reperfusion; LSTS: Local somatothermal stimulation; AST: Aspartate aminotransferase; ALT: Alanine aminotransferase; IP: Intraperitoneal injection; MDA: Malondialdehyde; GSH: Glutathione; CAT: Catalase; SOD: Superoxidase dismutase; MPO: Myeloperoxidase; ROS: Reactive oxygen species; H \& E: Hematoxylin \& Eosin. 


\section{Competing interests}

All authors declare that there are no financial competing interests.

\section{Authors' contributions}

Each of these authors has contributed equally to this article. CC carried out the I/R injury mechanism studies, acquisition of data, or analysis and interpretation of data, and drafted the manuscript. JH participated in the design of the study, performed the statistical analysis and helped to proofread the manuscript. SC and YL participated in its design and coordination and helped to draft the manuscript. All authors read and approved the final manuscript.

\section{Acknowledgements}

This work was supported by the grants from National Science Concil, Taiwan, R.O.C and Veterans General Hospital, Taipei, Taiwan, R.O.C. (NSC93-2320-B010-071, 94-2320-B-010-016, VGHUST96-G7-2, NSC102-2320-B-002-014).

\section{Author details}

${ }^{1}$ Department and Institute of Veterinary Medicine, School of Veterinary Medicine, National Taiwan University, Taipei 106, Taiwan. ${ }^{2}$ Biologics Division, Animal Health Research Institute, Council of Agriculture, Executive Yuan, New Taipei City 251, Taiwan. ${ }^{3}$ Institute of Food Science and Technology, National Taiwan University, Taipei 106, Taiwan. ${ }^{4}$ Division of General Surgery, Department of Surgery, Veterans General Hospital, Taipei 112, Taiwan. ${ }^{5}$ Institute of Traditional Medicine, School of Medicine, National Yang-Ming University, Taipei 112, Taiwan.

Received: 21 June 2013 Accepted: 6 January 2014 Published: 13 January 2014

\section{References}

1. de la Monte SM, Arcidi JM, Moore GW, Hutchins GM: Midzonal necrosis as a pattern of hepatocellular injury after shock. Gastroenterology 1984, 86(4):627-631.

2. Yoshikawa T, Murakami M, Yoshida N, Seto O, Kondo M: Effects of superoxide dismutase and catalase on disseminated intravascular coagulation in rats. Thromb Haemost 1983, 50(4):869-872.

3. Arthur MJ: Reactive oxygen intermediates and liver injury. J Hepatol 1988, 6(1):125-131.

4. Jungermann K, Kietzmann T: Oxygen: modulator of metabolic zonation and disease of the liver. Hepatology 2000, 31(2):255-260.

5. Lemasters JJ, Ji S, Thurman RG: Centrilobular injury following hypoxia in isolated, perfused rat liver. Science 1981, 213(4508):661-663.

6. Gonzalez-Flecha B, Cutrin JC, Boveris A: Time course and mechanism of oxidative stress and tissue damage in rat liver subjected to in vivo ischemia-reperfusion. J Clin Invest 1993, 91(2):456-464.

7. Halliwell B: Reactive oxygen species in living systems: source, biochemistry, and role in human disease. Am J Med 1991, 91(3C):14S-22S.

8. McCord JM: Oxygen-derived free radicals in postischemic tissue injury. N Engl J Med 1985, 312(3):159-163.

9. Vollmar B, Glasz J, Leiderer R, Post S, Menger MD: Hepatic microcirculatory perfusion failure is a determinant of liver dysfunction in warm ischemiareperfusion. Am J Pathol 1994, 145(6):1421-1431.

10. Jaattela M, Wissing D, Kokholm K, Kallunki T, Egeblad M: Hsp70 exerts its anti-apoptotic function downstream of caspase-3-like proteases. EMBO J 1998, 17(21):6124-6134.

11. Inoue M, Kitakoji $H$, Yano $T$, Ishizaki N, Itoi M, Katsumi $Y$ : Acupuncture treatment for low back pain and lower limb symptoms-the relation between acupuncture or electroacupuncture stimulation and sciatic nerve blood flow. Evid Based Complement Alternat Med 2008, 5(2):133-143.

12. Hua JS, Li LP, Zhu XM: Effects of moxibustion pretreating on SOD and MDA in the rat of global brain ischemia. J Tradit Chin Med 2008, 28(4):289-292

13. Pang $Y$, Wu LB, Liu DH: Acupuncture therapy for apoplectic aphasia: a systematic review. Zhongguo Zhen Jiu 2010, 30(7):612-616.

14. Berman BM, Langevin HM, Witt CM, Dubner R: Acupuncture for chronic low back pain. N Engl J Med 2010, 363(5):454-461.

15. Lee MS, Choi TY, Kang JW, Lee BJ, Ernst E: Moxibustion for treating pain: a systematic review. Am J Chin Med 2010, 38(5):829-838.

16. Beyerman KL, Palmerino MB, Zohn LE, Kane GM, Foster KA: Efficacy of treating low back pain and dysfunction secondary to osteoarthritis: chiropractic care compared with moist heat alone. J Manipulative Physiol Ther 2006, 29(2):107-114

17. Yeh CC, Ko SC, Huh BK, Kuo CP, Wu CT, Cherng CH, Wong CS: Shoulder tip pain after laparoscopic surgery analgesia by collateral meridian acupressure (shiatsu) therapy: a report of 2 cases. J Manipulative Physiol Ther 2008, 31(6):484-488.

18. Arroyo-Morales M, Olea N, Martinez M, Moreno-Lorenzo C, Diaz-Rodriguez L, Hidalgo-Lozano A: Effects of myofascial release after high-intensity exercise: a randomized clinical trial. J Manipulative Physiol Ther 2008, 31(3):217-223.

19. Pfefer MT, Cooper SR, Uhl NL: Chiropractic management of tendinopathy: a literature synthesis. J Manipulative Physiol Ther 2009, 32(1):41-52.

20. Pan PJ, Chan RC, Yang AH, Chou CL, Cheng YF, Chiu JH: Protective effects of preconditioned local somatothermal stimulation on neuromuscular plasticity against ischemia-reperfusion injury in rats. J Orthop Res 2008, 26(12):1670-1674.

21. Lin YH, Chiu JH, Tung HH, Tsou MT, Lui WY, Wu CW: Preconditioning somatothermal stimulation on right seventh intercostal nerve territory increases hepatic heat shock protein 70 and protects the liver from ischemia-reperfusion injury in rats. J Surg Res 2001, 99(2):328-334.

22. Chiu JH, Lui WY, Chen YL, Hong CY: Local somatothermal stimulation inhibits the motility of sphincter of Oddi in cats, rabbits and humans through nitrergic neural release of nitric oxide. Life Sci 1998, 63(6):413-428.

23. Chiu JH, Tsou MT, Tung HH, Tai CH, Tsai SK, Chih CL, Lin JG, Wu CW: Preconditioned somatothermal stimulation on median nerve territory increases myocardial heat shock protein 70 and protects rat hearts against ischemia-reperfusion injury. J Thorac Cardiovasc Surg 2003, 125(3):678-685.

24. Jiang JK, Chiu JH, Lin JK: Local somatothermal stimulation inhibits motility of the internal anal sphincter through nitrergic neural release of nitric oxide. Dis Colon Rectum 2000, 43(3):381-388.

25. Hiratsuka M, Yano M, Mora BN, Nagahiro I, Cooper JD, Patterson GA Heat shock pretreatment protects pulmonary isografts from subsequent ischemia-reperfusion injury. J Heart Lung Transplant 1998 17(12):1238-1246.

26. Canada AT, Stein K, Martel D, Watkins WD: Biochemical appraisal of models for hepatic ischemia-reperfusion injury. Circ Shock 1992 36(3):163-168

27. Chiu $\mathrm{JH}, \mathrm{Ho} C \mathrm{CT}$, Wei $Y H$, Lui WY, Hong CY: In vitro and in vivo protective effect of honokiol on rat liver from peroxidative injury. Life Sci 1997, 61(19):1961-1971.

28. Hillegass LM, Griswold DE, Brickson B, Albrightson-Winslow C: Assessment of myeloperoxidase activity in whole rat kidney. J Pharmacol Methods 1990, 24(4):285-295.

29. Koo A, Komatsu H, Tao G, Inoue M, Guth PH, Kaplowitz N: Contribution of no-reflow phenomenon to hepatic injury after ischemia-reperfusion: evidence for a role for superoxide anion. Hepatology 1992, 15(3):507-514

30. Deshaies RJ, Koch BD, Werner-Washburne M, Craig EA, Schekman R: A subfamily of stress proteins facilitates translocation of secretory and mitochondrial precursor polypeptides. Nature 1988, 332(6167):800-805.

31. Wienhues U, Neupert W: Protein translocation across mitochondrial membranes. Bioessays 1992, 14(1):17-23.

32. Jaeschke $\mathrm{H}$ : Molecular mechanisms of hepatic ischemia-reperfusion injury and preconditioning. Am J Physiol Gastrointest Liver Physiol 2003, 284(1):G15-G26

33. Liu Z, Xu Z, Shen W, Li Y, Zhang J, Ye X: Effect of pharmacologic preconditioning with tetrandrine on subsequent ischemia/reperfusion injury in rat liver. World J Surg 2004, 28(6):620-624.

34. Oreopoulos GD, Wu H, Szaszi K, Fan J, Marshall JC, Khadaroo RG, He R, Kapus A, Rotstein OD: Hypertonic preconditioning prevents hepatocellular injury following ischemia/reperfusion in mice: a role for interleukin 10. Hepatology 2004, 40(1):211-220.

35. Takahashi Y, Tamaki T, Tanaka M, Konoeda Y, Kawamura A, Katori M, Kakita A Efficacy of heat-shock proteins induced by severe fasting to protect rat livers preserved for 72 hours from cold ischemia/reperfusion injury. Transplant Proc 1998, 30(7):3700-3702.

36. Vajdova $K$, Heinrich S, Tian Y, Graf R, Clavien PA: Ischemic preconditioning and intermittent clamping improve murine hepatic microcirculation and Kupffer cell function after ischemic injury. Liver Transp/ 2004, 10(4):520-528 
37. Latchman DS: Heat shock proteins and cardiac protection. Cardiovasc Res 2001, 51(4):637-646.

38. Parsell DA, Lindquist $\mathrm{S}$ : The function of heat-shock proteins in stress tolerance: degradation and reactivation of damaged proteins. Annu Rev Genet 1993, 27:437-496.

39. Russell WJ, Jackson RM: MnSOD protein content changes in hypoxic/ hypoperfused lung tissue. Am J Respir Cell Mol Biol 1993, 9(6):610-616.

40. Knowlton AA, Kapadia S, Torre-Amione G, Durand JB, Bies R, Young J, Mann $D L$ : Differential expression of heat shock proteins in normal and failing human hearts. J Mol Cell Cardiol 1998, 30(4):811-818.

41. Weisiger RA, Fridovich I: Superoxide dismutase, organelle specificity. J Biol Chem 1973, 248(10):3582-3592.

42. Javadpour M, Kelly CJ, Chen G, Bouchier-Hayes DJ: Herbimycin-A attenuates ischaemia-reperfusion induced pulmonary neutrophil infiltration. Eur J Vasc Endovasc Surg 1998, 16(5):377-382.

43. Javadpour M, Kelly CJ, Chen G, Stokes K, Leahy A, Bouchier-Hayes DJ: Thermotolerance induces heat shock protein 72 expression and protects against ischaemia-reperfusion-induced lung injury. Br J Surg 1998, 85(7):943-946.

44. Chen G, Kelly C, Stokes K, Wang JH, Leahy A, Bouchier-Hayes D: Induction of heat shock protein $72 \mathrm{kDa}$ expression is associated with attenuation of ischaemia-reperfusion induced microvascular injury. J Surg Res 1997, 69(2):435-439.

45. Stojadinovic A, Kiang J, Smallridge R, Galloway R, Shea-Donohue T: Induction of heat-shock protein 72 protects against ischemia/reperfusion in rat small intestine. Gastroenterology 1995, 109(2):505-515.

46. Weiss SJ, Ward PA: Immune complex induced generation of oxygen metabolites by human neutrophils. Journal of immunology 1982, 129(1):309-313.

47. Heinzelmann M, Mercer-Jones MA, Passmore JC: Neutrophils and renal failure. Am J Kidney Dis 1999, 34(2):384-399.

48. Zimmerman BJ, Grisham MB, Granger DN: Role of oxidants in ischemia/ reperfusion-induced granulocyte infiltration. Am J Physiol 1990, 258(2 Pt 1):G185-G190.

doi:10.1186/1472-6882-14-18

Cite this article as: Hsieh et al:: Preconditioning somatothermal stimulation on Qimen (LR14) reduces hepatic ischemia/reperfusion injury in rats. BMC Complementary and Alternative Medicine 2014 14:18.

\section{Submit your next manuscript to BioMed Central and take full advantage of:}

- Convenient online submission

- Thorough peer review

- No space constraints or color figure charges

- Immediate publication on acceptance

- Inclusion in PubMed, CAS, Scopus and Google Scholar

- Research which is freely available for redistribution 